\title{
CS modality, context conditioning, and conditioned freezing
}

\author{
RONALD A. SIGMUNDI and ROBERT C. BOLLES \\ University of Washington, Seattle, Washington
}

\begin{abstract}
Two studies used a one-trial-a-day aversive conditioning procedure with rats as subjects to investigate the effects of a noise versus a light CS on conditioned freezing. Experiment 1 demonstrated that less conditioned freezing was elicited by the light, although the two CSs led to similar levels of freezing to the contextual cues of the conditioning chamber. Experiment 2 replicated these outcomes and showed that the manipulation of CS intensity produced results similar to those of modality, with the more intense CSs eliciting less freezing. The second experiment also determined that freezing to contextual cues resulted from context conditioning. According to the Rescorla-Wagner model, CSs that condition poorly should generate little competition with context conditioning. Since neither the modality nor intensity factor reliably influenced context conditioning, as measured by context-evoked freezing, the studies provide no support for the view that the effects on CS-evoked freezing represent differences in the strength of conditioning to the various stimuli. This finding raises the possibility that all of the CSs conditioned well but varied in their abilities to elicit freezing because they differed in terms of the form of defensive behavior under their control.
\end{abstract}

A number of studies indicate that aversive conditioning outcomes can vary on the basis of whether a noise or a light is the CS (e.g., Linwick, Patterson, \& Overmier, 1981; Shettleworth, 1972; Sigmundi, Bouton, \& Bolles, 1980). Immediately one has the option of determining the nature of the CS characteristics responsible for the effect. They might be intrinsic to the modality of the CS, or they might involve variables such as CS intensity, location, and localizability that can vary independently of modality and that are known to influence performance in Pavlovian settings (Holland, 1977; Kamin, 1969; Karpicke, Cristoph, Peterson, \& Hearst, 1977). In few cases have the critical characteristics been identified. The present report will tend to default on this option and will use the term "CS modality effect," in a general sense, to refer to noise-light differences in conditioning but with no implications about the nature of the stimulus features responsible for the effect. We are more interested in a second task generated by the occurrence of a CS modality effect, that of determining the nature of the underlying behavior processes. While several interesting approaches to this problem have been discussed and implemented (e.g., Holland, 1977, 1979; Jacobs \& LoLordo, 1980; Linwick et al., 1981),

This article is based on a dissertation by the first author submitted to the University of Washington in partial fulfillment of the PhD requirements. The research was supported in part by National Science Foundation Grant BNS76-19912. Requests for reprints should be sent to Ronald A. Sigmundi, Department of Psychology, University of Toronto, Toronto, Ontario M5S 1 A1, Canada. we will focus on the question of whether the modality effect reported by Sigmundi et al. (1980) represents a difference in the strength of conditioning to noise and light or a difference in the topography (i.e., form) of behavior controlled by the two CSs. A brief background to this question is provided by the work of Holland $(1977,1979)$.

In 1979, Holland reported an extension from the appetitive to the aversive case of his examination of a methodology in which a light and tone both conditioned well but controlled different forms of conditioned responding. The light elicited more rearing and fewer startle responses than the tone. These differences reflected different CS-characteristic startle and orienting responses that were correlated with CS onset and that were present in both the conditioned and the unconditioned responses to the CSs. Excitatory conditioning enhanced these responses, but in later portions of the CS, the modality effect disappeared as each stimulus elicited behavior appropriate to the US, freezing in the case of shock (see Bouton \& Bolles, 1981). One aspect of these findings is that they blur the distinction between conditioned and unconditioned responding. A second important aspect is that they emphasize that the choice of CS can influence response selection in Pavlovian procedures.

Whereas Holland found no difference in the level of conditioned freezing to a tone and light, Sigmundi et al. (1980) reported a procedure in which less conditioned freezing was elicited by a light than by a white noise. As danger signals, both the light and noise produced reliably more freezing than novel 
CS controls, but freezing to the noise increased with shock intensity, while freezing to the light did not. These outcomes might mean that the noise and light controlled different forms of conditioned responding, a possibility suggested by the data of Holland. Alternatively, it may be that the light conditioned more poorly than the noise, a possibility suggested by the work of Jacobs and LoLordo (1980) on tonelight differences in the conditioned acceleration of avoidance responding. The present report examined the latter alternative, using a compound conditioning procedure to test a prediction from the RescorlaWagner model (Rescorla, 1972).

According to the Rescorla-Wagner model, the relative strength of conditioning to two stimuli might be determined by assessing the degree to which each CS competes with conditioning to other stimuli in the predictive stimulus complex. We used this approach by monitoring context conditioning to the static apparatus cues of the conditioning chamber. If the light produces less competition with context conditioning than the noise, this would support the view that the light is the poorer CS.

\section{EXPERIMENT 1}

Aversive conditioning studies with rats have produced repeated demonstrations that a discrete CS can impede context conditioning (Baker, Mercier, Gabel, \& Baker, 1981; Marlin, 1981; Odling-Smee, $1978 \mathrm{a}, 1978 \mathrm{~b})$. While recognizing that these demonstrations may have little generality to other conditioning preparations, such as autoshaping with pigeons (Jenkins, Barnes, \& Barrera, 1981), the present report is concerned with aversive conditioning and with rats, so the context conditioning approach seems justified. We used a one-trial-aday aversive conditioning procedure because preliminary work had demonstrated that this procedure generates a considerable amount of freezing to apparatus cues prior to the daily CS presentation. Since freezing to apparatus cues has been shown to reflect context conditioning (Blanchard \& Blanchard, 1969; Bolles \& Collier, 1976; Fanselow, 1981; Fanselow \& Baackes, 1982), the one-trial-aday procedure provides a convenient methodology for assessing context conditioning.

In the first phase of the study, two forward conditioning groups received a daily presentation of either noise or light, followed by shock. Two CSalone groups received either the noise or the light but no shock. In Phase 2, one-half of the animals in each of the forward conditioning groups were tested with the same CS they had received during conditioning, while the remaining animals from the two groups constituted novel CS controls and were presented with the noise or the light for the first time.
If the results of Sigmundi et al. (1980) extend to the present procedure, the noise should elicit more CS-evoked freezing than the light. As a conditioning phenomenon, this outcome should appear in the forward conditioning groups; however, any involvement of the unconditioned responses to the noise and light might also appear in the CSalone and novel CS groups. Pre-CS freezing scores were used to measure context conditioning and to infer the strength of conditioning to the noise and light. If forward conditioning with the light, as opposed to the noise, leads to more pre-CS freezing, this would provide support for the view that the light is a poorer CS than the noise.

\section{Method}

Subjects. Twenty-four male rats of Wistar descent were individually housed on a 12/12-h light/dark cycle with free access to food and water. The rats were about 150 days old at the start of the study.

Apparatus. Two conditioning boxes (Box A, $20 \times 24 \times 20 \mathrm{~cm}$ high; Box B, $24 \times 30 \times 22 \mathrm{~cm}$ high) were housed in soundattenuating chambers. The side walls of the boxes were made of stainless steel, while the front walls, rear walls, and ceilings were made of clear acrylic plastic. The boxes were continuously lighted by 7.5-W red houselights, one of which was located above each ceiling. A white noise served as one of the conditioned stimuli. Its intensity was about $69 \mathrm{~dB}$ relative to a 35-dB background in Box $A$ and about $71 \mathrm{~dB}$ relative to a 30-dB background in Box B (A scale). It was delivered by a Grason-Stadler $455 \mathrm{C}$ noise generator through two speakers, one of which was located above the ceiling of each box. A second CS was provided by the onset of a 30-W white incandescent light located about $20 \mathrm{~cm}$ above each ceiling. Scrambled grid shock was delivered through the stainless steel grid floor of each box by either of two GrasonStadler E6070B shock generators. The grid floors were made of $3-\mathrm{mm}$ steel rods, spaced $1.3 \mathrm{~cm}$ center to center. Each of the attenuating chambers had a clear plastic window through which the rats could be observed.

Procedure. The study was run during the light portion of the 24-h cycle. The first phase of the study lasted for eight trials, one trial a day. The onset of a 30-sec CS occurred $180 \mathrm{sec}$ into each 6-min session. CS termination was simultaneous with the onset of a .8-mA, .5-sec, scrambled grid shock for two conditioning groups $(n s=8)$. No shock was delivered to two habituation groups $(n s=4)$. One conditioning group, N-8, and one habituation group, $\mathrm{N}-0$, received the white noise as the $\mathrm{CS}$. The second conditioning group, L-8, and the second habituation group, L-0, received onset of the white light as the CS. After every session, the interiors of the boxes were cleaned with a dilute vinegar solution and a damp sponge.

Then a test session was administered on Day 9. The onset of a $30-\mathrm{sec} \mathrm{CS}$ occurred $180 \mathrm{sec}$ into the 6-min session, as in Phase 1. One-half of the animals $(n=4)$ in Group $N-8$ were tested with the white noise. This group is labeled $N-8 / N$ in the test session. The remaining four animals in Group N-8 were tested with the light. This group is labeled $\mathrm{N}-8 / \mathrm{L}$ in the test session. Group L-8 was similarly divided into two groups of four rats. Group L-8/L was tested with the light, and Group L-8/N was tested with the white noise. Groups $L-8 / N$ and $N-8 / L$ constituted novel $\mathrm{CS}$ controls against which to compare the effects of conditioning. Groups $\mathrm{N}-0$ and $\mathrm{L}-0$ did not participate in the test session, having accomplished their function as conditioning control groups during Phase 1 of the study.

Freezing (lack of movement, except for breathing) was sampled by an observer every third second during the 30 -sec period immediately prior to each CS presentation and for the 30-sec dura- 
tion of a CS. Samples on which no freezing was observed were scored simply as activity.

\section{Results}

The light elicited less CS freezing than the noise in the forward-conditioning groups in both phases of the study, but not in the novel-CS and CS-alone controls, in which little freezing occurred. A tendency toward less pre-CS freezing with the light than with the noise in the forward-conditioning groups during Phase 1 failed to reach a conventional level of significance.

The data were treated with separate analyses for pre-CS and CS scores in both the conditioning phase and the test session. Suppression ratios were not used, since they are invalidated by pre-CS differences in performance, and this research was directed at pre-CS differences. Each of the four analyses consisted of a set of three orthogonal t tests on treatment means, evaluated with two-tailed critical regions, and using standard errors and degrees of freedom based on the pooled within-treatment sum of squares (Edwards, 1972, p. 137). There were 20 df in Phase 1 and 12 in Phase 2. Pooling was appropriate, since Bartlett's test (Winer, 1962, p. 95) produced no reliable evidence of heterogeneity of variance in any of the four analyses $\left[x^{2}(3)<7.29\right.$, $\mathrm{p}>$.05].

Pre-CS scores from Phase 1 are plotted in Figure $1 .^{1}$ Collapsed over trials, more pre-CS freezing occurred in the conditioning groups (N-8 and L-8) than in the habituation controls (Groups $\mathrm{N}-0$ and $\mathrm{L}-0)(\mathrm{t}=2.52, \mathrm{p}<.05)$. The tendency toward more pre-CS freezing in Group $\mathbf{N}-8$ than in Group L-8 fell short of significance $(t=1.86, .05<p<.10)$. There was no reliable difference in pre-CS freezing between Groups $\mathrm{N}-0$ and $\mathrm{L}-0(\mathrm{t}<1)$.

CS scores from Phase 1 are plotted in Figure 2. Collapsed over trials, the conditioning groups (N-8

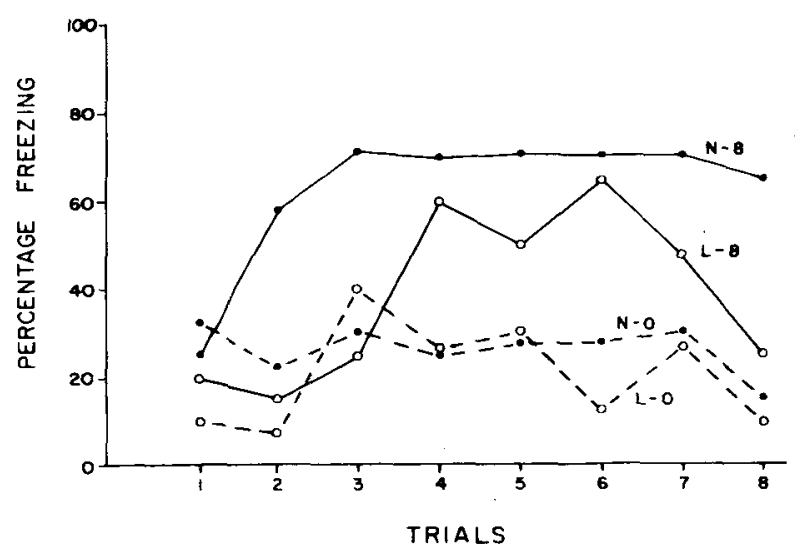

Figure 1. Acquialtion of group mean pre-CS freezing as a function of CS modality [either a white noise (N) or a light (L) was followed by either a 0- or a .8-mA shock on each trial].

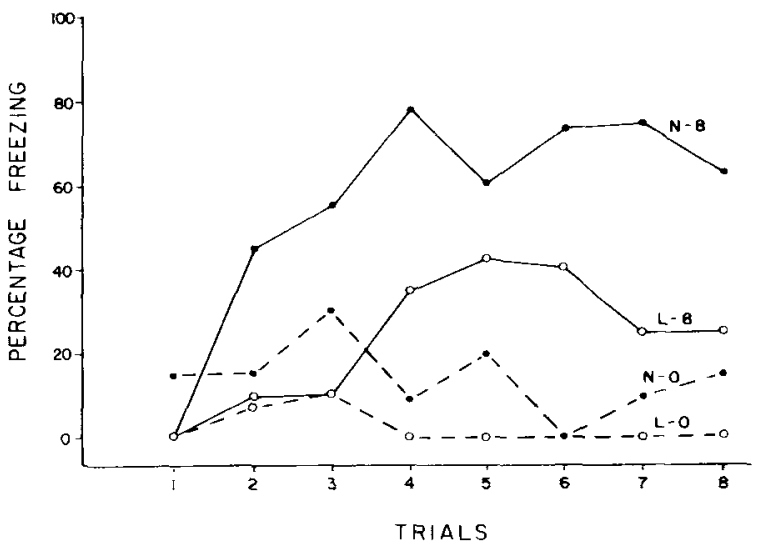

Figure 2. Acquilition of group mean CS freeding as a function of CS modality [either a white nolse (N) or a light (L) was followed by either a 0- or a .8-mA shock on each trial].

and L-8) froze more during CS presentations than the habituation controls (Groups N-0 and L-0) $(t=5.08, p<.01)$. More CS freezing occurred in Group N-8 than in Group L-8 $(t=4.33, p<.01)$, but Groups $\mathrm{N}-\mathrm{O}$ and $\mathrm{L}-\mathrm{O}$ did not differ reliably $(\mathrm{t}=$ $1.10, \mathrm{p}>.20$ ).

Results from the test session are presented in Figure 3. More CS freezing occurred in the conditioning groups $(\mathrm{N}-8 / \mathrm{N}$ and $\mathrm{L}-8 / \mathrm{L})$ than in the novelCS controls (Groups $N-8 / L$ and $L-8 / N)(t=4.74$, $\mathrm{p}<.01)$. Group $\mathrm{N}-8 / \mathrm{N}$ froze more during the $\mathrm{CS}$ than did Group $L-8 / L(t=4.44, p<.01)$, but there was no reliable difference in CS freezing between Groups $N-8 / L$ and $L-8 / N(t<1)$. None of these three comparisons revealed significant differences when pre-CS data were analyzed (ts $<1.02$ ).

\section{Discussion}

The one-trial-a-day procedure appears to be an effective aversive conditioning procedure. More CS-evoked freezing occurred in the forwardconditioning groups than in the CS-alone or the novel-CS controls. These outcomes indicate that CS-evoked freezing resulted from Phase 1 exposures to shock and that freezing was specific to the CS that was paired with shock. These outcomes also indicate that freezing is a conditioned defense reaction elicited by aversive CSs. It is unlikely that the immobility that we recognized as freezing in Group N-8/N (see Figure 3) resulted from the rats' being asleep or bored, for why would rats sleep in such a dangerous situation but not in the presence of innocuous stimuli which were never paired with shock, as in the case of Groups $\mathrm{N}-0$ and $\mathrm{L}-\mathrm{O}$ (see Figure 2)? The most reasonable view of the pattern of CS data is that the procedure was effective in conditioning freezing as a defense reaction.

In regard to noise-light differences, the reliable modality effect on CS freezing was confined to the 


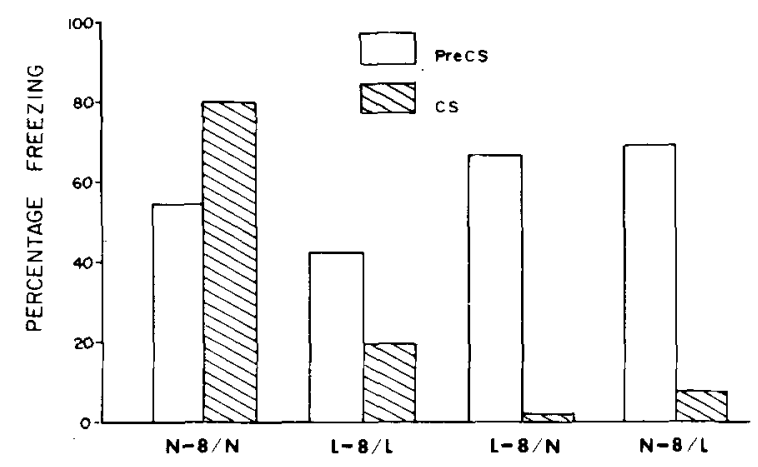

GROUP

Figure 3. Group mean freezing in pre-CS and CS periods in a postconditioning test session. [Animals were tested with the noise after being conditioned with either a noise (Group N-8/N) or a light CS (Group L-8/N), or they were tested with a light after being conditioned with either the noise (Group $\mathrm{N}-8 / \mathrm{L}$ ) or light CS (Group L-8/L.1

forward-conditioning groups, while little CS freezing occurred in the CS-alone and novel-CS controls. One can conclude that the modality effect is not due to different levels of unconditioned freezing to the two CSs; however, the unconditioned responses could still be involved. For example, the light might elicit more unconditioned activity than the noise to interfere with a conditioned response of freezing.

Consistent with this possibility, the pre-CS freezing data provide no evidence to indicate that the light was a poor CS; in fact, there tended to be less pre-CS freezing in the forward-conditioning groups in Phase 1 when the light, rather than the noise, was the CS. According to the Rescorla-Wagner model, this type of outcome indicates that the light conditioned at least as well as the noise. However, since the pre-CS modality effect did not reach the conventional .05 level of significance, a strong possibility remains that the light conditioned more poorly than the noise, while the pre-CS freezing measure was insensitive to the differences. Because of the equivocal nature of the pre-CS data, the following study again tested the compound conditioning hypothesis.

\section{EXPERIMENT 2}

This study provided two extensions of the design of Experiment 1. The major one was the addition of context conditioning control groups to provide assurance that pre-CS freezing reflects context conditioning. Second, CS intensity was manipulated to provide a preliminary investigation of the possibility that the noise-light difference is caused by the relative intensities of the CSs, rather than by stimulus characteristics that are intrinsic to CS modality (e.g., Kamin, 1969).
The study was divided into two phases, acquisition and context extinction. Acquisition used the one-trial-a-day procedure and, disregarding the trial factor, employed a $2 \times 2$ independent groups design with a modality factor (noise vs. light) and a CS intensity factor (low vs. high intensity). To the extent that intensity and modality produce similar effects on both pre-CS and CS performance, the possibility will exist that the modality effect is due to the relative intensities of the noise and light.

During the 8 days of context extinction, four animals from each of the acquisition groups received a daily extinction session in their conditioning chamber with no CSs or USs programmed. An additional four animals from each of the acquisition groups underwent extinction sessions in a novel box (boxes were counterbalanced). If freezing to apparatus cues is due to context conditioning, then freezing should show specificity to the conditioning chamber during extinction. That is to say, generalization decrement should facilitate the decline in freezing during extinction for animals that receive extinction sessions in the novel box.

The remaining animals from the acquisition groups were used as nonextinction controls, spending the first 6 days of the context extinction phase in their home cages with no exposure to the conditioning chambers or the novel boxes. On the final 2 days of this phase, these animals received extinction sessions in their conditioning chambers. When compared with the two extinction groups, the nonextinction controls should reveal the extent to which the effects of shock on freezing dissipate with the passage of time in the home cage. If the nonextinction control group exhibits more freezing than the extinction groups on the final 2 days of the context extinction phase, then the extinction of freezing cannot be due solely to the dissipation over time of the direct, nonassociative effects of shock. Rather, the extinction of freezing would be specific to nonreinforced presentations of the extinction context, reflecting a loss of excitation to contextual cues that had accrued in acquisition through pairings of the conditioning chamber with shock. That is to say, the extinction of freezing would be context specific. This design, then, looks at the effects of CS modality and intensity on pre-CS and CS freezing. Furthermore, by assessing the context specificity of both freezing and the extinction of freezing, the design examines whether freezing to contextual cues represents context conditioning rather than a nonassociative effect of shock.

\section{Method}

Subjects. Forty female rats of Wistar descent were about 120 days old at the start of the study. They were housed and maintained as in Experiment 1.

Apparatus. The conditioning chambers were the same as in Experiment 1 except for some changes in Box $B$ that were made in an attempt to insure that the rats could distinguish easily be- 
tween the two boxes. Box B measured $23 \times 26 \times 26 \mathrm{~cm}$ high and contained a stainless steel grid floor made of $6-\mathrm{mm}$ rods, spaced $1.5 \mathrm{~cm}$ center to center.

A high-intensity light CS was provided by the onset of a $40-\mathrm{W}$ white incandescent light, while a low-intensity light CS was provided by the onset of a 7.5-W white incandescent light. A whitenoise $C S$ was also delivered either at a high or a low intensity. In Box A, the background noise level was $35 \mathrm{~dB}$, the high-intensity white noise was $69 \mathrm{~dB}$, and the low-intensity white noise was $60 \mathrm{~dB}$. In Box $\mathrm{B}$, the background noise level was $30 \mathrm{~dB}$, the high-intensity white noise was $71 \mathrm{~dB}$, and the low-intensity white noise was $62 \mathrm{~dB}$ (A scale). The apparatus was otherwise the same as in Experiment 1.

Procedure. The study was run during the light portion of the 24-h cycle and consisted of an acquisition phase, followed by a context extinction phase. In acquisition, each rat received a series of seven conditioning trials, one trial a day. On each conditioning trial, the onset of a $45-\mathrm{sec}$ CS occurred $180 \mathrm{sec}$ into a 6-min session. The CS duration was increased to $45 \mathrm{sec}$ in this study to provide more time in which to collect and record each sample of behavior. CS termination was simultaneous with the onset of a .5-sec, .8-mA scrambled grid shock. Freezing was sampled every $4.5 \mathrm{sec}$ during a $45-\mathrm{sec}$ period immediately prior to each CS and for the 45-sec duration of the CS. After each session in acquisition and in the subsequent extinction phase, the interior of Box $\mathbf{A}$ was cleaned with a dilute vinegar solution and the interior of Box B was cleaned with Windex. Two cleaning solutions were used to provide each box with a distinctive odor so that during extinction the rats might readily distinguish a novel box from the conditioning chamber.

Four acquisition groups differed on the basis of which CS they received during conditioning. Group HN $(n=8)$ received the high-intensity noise for a CS; Group HL $(n=8)$ received the high-intensity light; Group LN $(n=12)$, the low intensity noise; and Group LL $(n=12)$, the low-intensity light.

Acquisition was followed by an 8-day context extinction phase, one session a day, during which no CSs and no USs were programmed. Freezing was sampled every $4.5 \mathrm{sec}$ for a 45 -sec period beginning $135 \mathrm{sec}$ into each extinction session; however, no data were recorded for animals in one of the groups (Group HC) on the first 6 days of the context extinction phase, which these animals spent in their home cages.

Groups in the context extinction phase were formed as follows, with the groups being matched on the basis of each animal's average performance on the last two trials of the acquisition phase. Four animals from each of the acquisition groups received one extinction session a day for 8 days in their conditioning chambers (Group CC, $n=16$ ). Another four animals from each of the acquisition groups received their eight extinction sessions in a novel box (Group NB, $n=16$ ). Thus, animals in Groups $C C$ and NB were counterbalanced on the basis of the CS modality and intensity they had received in acquisition. Furthermore, Boxes A and B were counterbalanced, each serving as the conditioning chamber for one-half of the animals and as the novel box for the remaining animals. The extent to which Group CC exhibits more freezing to apparatus cues than Group NB over the course of extinction provides an indication of the context specificity of freezing.

The final four animals from Acquisition Groups LL and LN spent the first 6 days of the context extinction phase in their home cages, before being tested on Days 7 and 8 in their conditioning chambers. These animals formed Group HC $(n=8)$, which was counterbalanced on the basis of CS modality in acquisition, but which contained only animals that had received low-intensity CSs in acquisition. The performance of animals in Group HC on Days 7 and 8 of the context extinction phase reflects the extent to which freezing to apparatus cues can dissipate over the course of 6 days in the home cage with no exposure to the extinction chambers. A comparison of performance between Group $\mathrm{HC}$ and Group $\mathrm{CC}$ in the conditioning chambers on Days 7 and 8 provides a measure of the context specificity of the extinction of freezing. This comparison indicates whether the extinction of freezing to apparatus cues depends on unreinforced exposures to those cues, rather than merely the passage of time in the home cages since the last shock. Of course, the comparison between Groups $\mathrm{HC}$ and $\mathrm{CC}$ can involve only those animals that received low-intensity CSs in acquisition, since Group HC was made up solely of such animals.

In summary, the context extinction phase was designed to determine whether freezing to apparatus cues can reasonably be regarded as the result of context conditioning. This determination was based on an evaluation of the context specificity of freezing and the context specificity of the extinction of freezing.

During the context extinction phase, the observer was blind to the treatment condition assigned to each animal. On the second extinction trial, a second blind observer time-sampled freezing in order to provide an interobserver reliability check of the response measure.

\section{Results}

Acquisition phase. In acquisition, both the CS modality and CS intensity factors reliably influenced the level of CS-evoked freezing. The noise elicited more freezing than did the light, while the low-intensity CSs elicited more freezing than did those of high intensity. However, for the pre-CS data, the effects of neither modality nor intensity reached a conventional level of significance. The acquisition data are shown in Figure 4 as a function of two-trial blocks; pre-CS scores are in the left panel, and CS scores are in the right.

The statistical analysis proceeded as follows. CS data were collapsed over trial blocks and analyzed with a $2 \times 2$ (modality $\times$ intensity) independent groups ANOVA for unequal ns (Edwards, 1972, p. 217). The modality factor produced a reliable effect $[F(1,36)=29.04, p<.01]$, whereas neither the main effect of intensity nor the modality $\times$ intensity interaction was significant $[\mathrm{Fs}(1,36)<2.64$, ps $>.10]$. However, on the last trial block of acquisition, the intensity factor was significant $[F(1,36)$ $=5.78, \mathrm{p}<.025]$.

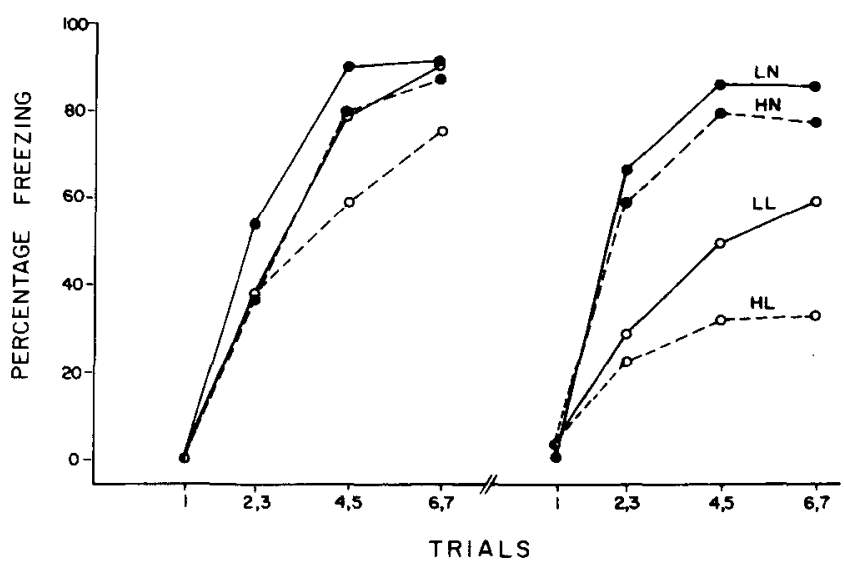

Figure 4. Acquisition of group mean pre-CS (left panel) and CS (right panel) freezing as a function of CS modality and CS intensity. [Four groups were conditioned with low-intensity nolse (LN), a low-intensity light (LL), a high-intensity noise (HN), or a high-intensity light (HL) as the CS.I 
The analysis of pre-CS data, collapsed over trial blocks, indicated that both the modality and intensity factors fell short of significance $[\mathrm{Fs}(1,36)<3.33$, $.05<\mathrm{ps}<.10$ ]. The modality $\times$ intensity interaction was not significant $[\mathrm{F}(1,36)<1]$. On the last trial block of acquisition, an analysis of the modality and intensity factors showed that neither of the main effects or their interaction was significant in the pre-CS data $[F s(1,36)<2.48$, ps $>.10]$.

Context extinction phase. Freezing data during extinction are plotted in Figure 5 as a function of two-trial blocks. Data from each group are collapsed over CS modality, but not intensity, so that the figure readily depicts the comparison on Trial Block 4 between Group HC and those animals in Groups CC and NB that received low-intensity CSs in acquisition.

Inspection of the figure shows that freezing to apparatus cues over the course of extinction was context specific. Animals that received extinction sessions in their conditioning chambers (Group CC) froze more than those that experienced extinction sessions in a novel box (Group NB). On Trial Block 4, animals from Group HC froze more than their counterparts in Group CC. This indicates that exposures to the conditioning chambers on the first 6 days of the context extinction phase produced substantially larger decrements in freezing than can be accounted for by the mere passage of time in the home cages.

The analysis of the extinction data proceeded as follows. Data for each animal were grouped into two-trial blocks and were then converted to difference scores by subtracting performance on each trial block of extinction from performance on the

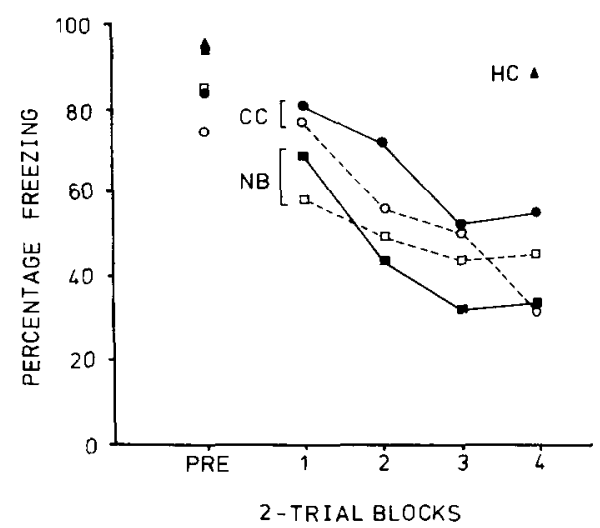

Figure 5. Group mean freezing scores to apparatus cues as a function of unreinforced exposures to the conditioning chamber (CC), a novel box (NB), or the home cages (HC). [Rats in Group HC were tested in the conditioning chamber on Trial Block 4. PRE scores show performance on the last trial block of acquisition. Closed symbols designate groups that received low-intensity CSs in acquisition, while open symbols refer to groups that received high-intensity CSs in acquisition.] last trial block of acquisition. Larger difference scores reflect larger decrements in freezing during extinction. Difference scores for Groups CC and NB were compared over the four trial blocks of extinction with a four-way mixed ANOVA that included the repeated trial-block factor and three independent factors: CS modality in acquisition (noise vs. light), CS intensity in acquisition (high vs. low), and extinction chamber (conditioning chamber vs. novel box). The analysis indicated that difference scores increased over trial blocks $[\mathrm{F}(3,72)=14.59$, $\mathrm{p}<.01]$. Furthermore, animals in Group NB had larger difference scores than those in Group $\mathrm{CC}$ $[F(1,24)=9.61, p<.01]$. This is indicative of the specificity of freezing to the conditioning chamber. None of the remaining main effects or interactions were reliable $[\mathrm{Fs}(1,24)<2.50$, ps $>.10 ; \operatorname{Fs}(3,72)$ $<1.77$, ps $>.10]$.

An ANOVA of difference scores on Trial Block 4, restricted to those animals that had received lowintensity CSs in acquisition, indicated that Groups $\mathrm{HC}, \mathrm{CC}$, and NB differed reliably $[\mathrm{F}(2,18)=16.11$, $p<.01]$. Neither the factor of modality in acquisition nor the group $\times$ modality interaction was significant (Fs $<1$ ). Pairwise comparisons showed that Group CC differed reliably from Group HC $[F(1,18)=4.44, p<.05]$ and from Group NB $[F(1,18)=12.33, p<.01]$. The latter comparison shows that the context specificity of freezing is still present on Trial Block 4 of extinction, while the former comparison is indicative of the context specificity of the extinction of freezing.

Freezing scores of 24 animals on the second extinction trial, based on the observations of two independent and blind observers, showed a high degree of interobserver reliability [Pearson $\mathrm{r}(23)=.99$ ]

\section{Discussion}

The effects of CS intensity were similar to those of modality both in CS and pre-CS periods, suggesting the possibility that the modality effect is related to the relative intensities of the noise and light, with the light being more intense than the noise. However, the analysis of this possibility is beyond the scope of the present report, and we have consigned the topic to future investigations of the modality effect.

Evidence from Experiment 2 indicates that freezing to apparatus cues in the one-trial-a-day procedure is caused by context conditioning. First, consider that exposure to shock was critical to contextevoked freezing. Pre-CS freezing developed during the acquisition phase when shock was present, while freezing to apparatus cues declined over extinction trials when shock was absent. This indicates that shock either supported context conditioning or produced nonassociative effects that caused freezing. The latter view is unlikely, since the effects of shock 
were context specific; greater decrements in freezing during extinction occurred in the novel boxes than in the conditioning chambers. Context specificity of this sort would not be expected from the nonassociative aspects of shock but follows directly from the alternative view that freezing in the presence of apparatus cues is caused by context conditioning. Additional support for the contextconditioning interpretation of pre-CS freezing is provided by the finding that the extinction of freezing was context specific. Group HC spent the first 6 days of the context extinction phase in the home cages. When tested on Days 7 and 8, the animals in Group HC showed a reliably smaller decline in freezing, relative to acquisition levels, than that shown by Group CC, which had received six prior unreinforced exposures to the conditioning chamber. If the extinction of freezing were caused primarily by the dissipation over time of nonassociative aspects of shock, then freezing in Group HC should have declined as much as that of Group CC. Instead, the obtained pattern of data is more consistent with the view that freezing to apparatus cues in the present procedure reflects context conditioning and that this conditioning extinguishes with repeated nonreinforced exposures to the apparatus cues.

Given that pre-CS freezing represents context conditioning, the light should lead to more pre-CS freezing than the noise if the light is the poorer CS. The present results provide no evidence to support the possibility that the light is a poorer CS than the noise. As in Experiment 1, the light and noise led to comparable levels of context conditioning. This may mean that the light is a good CS that elicits some form of conditioned response other than freezing or some form of unconditioned response that interferes with freezing. Alternatively, the light might, in fact, condition more poorly than the noise, while the pre-CS freezing index is insensitive to differences in the strength of conditioning to the two CSs. The results are still equivocal on this point. However, since the present report provides no evidence to support the view that the light is the poorer CS, we will examine several reasons why the light and noise might control conditioned responses that differ in form.

\section{GENERAL DISCUSSION}

Throughout these studies, consistently less freezing was elicited by the light than by the noise, supplementing information from an earlier report of a CS modality effect on conditioned freezing (Sigmundi et al., 1980). Since this outcome suggests that the noise and light might control different forms of behavior, one can inquire about the mechanisms that would enable a CS to influence response topography. The first consideration is that the unconditioned responses to the two CSs could be involved.
If the noise and light control unconditioned responses that differ in their ability to interfere with conditioned freezing, the modality effect would be a matter of peripheral response competition between the conditioned and unconditioned responses to each CS. This possibility was left open in the discussion sections of Experiments 1 and 2. A similar explanation, but one in which CS-characteristic unconditioned responses actually form part of the CR, might be formulated in terms of the mechanism examined by Holland $(1977,1979)$, which we described in the introduction.

A third way in which the unconditioned responses to a CS could influence the form of behavior would be if they functioned as preparatory responses to attenuate the aversiveness of shock. We will elaborate on this topic in a moment, but first, consider that the idea of a preparatory response points toward the potential importance of functional considerations in understanding the response selection of defensive behaviors. Hollis (1982) has emphasized in a convincing manner the importance of functional considerations in the explanation of behavior, particularly from a phylogenetic perspective. In this vein, Ratner (1967) has argued that the form of defensive behavior exhibited by a prey species such as the rat can be expected to vary with the proximity of the predator. When the predator is very far away, one can expect little defensive behavior from the prey. At a closer distance, the rat might engage in antidetection behavior such as freezing or hiding. As the predator draws nearer, flight might predominate, but when the predator is in contact with the rat, the rat should exhibit violent counterattack and escape behavior, possibly followed by tonic immobility (Ratner, 1967; Vestal, 1975).

Consider the application of Ratner's ideas to the present studies. It may be that, for rats, audition has evolved as a primary receptor for detecting predators at a distance so that many auditory CSs tend to control antidetection behavior such as freezing. On the other hand, the rat's visual system may have been phylogenetically ineffective as a distal sensor for predators. By the time a rat can see a predator, it might be too late to perform successful antidetection behaviors. If this were the case, then in the presence of visual danger signals, the rat should implement another defensive strategy such as moving to a safe place or preparing a counterattack. Such strategies would be difficult to recognize when testing the rat in a conditioning chamber that has no escape routes or places of safety, as in the present studies.

If, in general, visual signals for predation have been very much too late to enable the rat to avoid predatory attack, then a selective advantage should accrue to any anticipatory reaction that has reduced in phylogeny the debilitating effects of attack. Recent work indicates that this function might be ful- 
filled by an endogenous analgesic reaction in anticipation of aversive events (Bolles \& Fanselow, 1982; Fanselow \& Baackes, 1982). An analgesic reaction just prior to a predatory attack would serve temporarily to reduce the debilitating effects of injuries from the encounter by suppressing nociception. This would enhance the rat's ability to engage in defensive behavior when injured (Fanselow \& Sigmundi, 1982; Fanselow, Sigmundi, \& Bolles, 1980).

In terms of the present work, the light might exert more powerful control than the noise over either a conditioned or an unconditioned preparatory response to danger, a response such as an endogenous analgesic reaction. By attenuating the aversiveness of shock, the preparatory response to the light would reduce the magnitude of conditioned freezing, which varies directly with shock intensity (Sigmundi et al., 1980), to a level below that supported by the noise. The action of this mechanism would lead to an interesting state of affairs wherein the light conditioned well in the sense of becoming a reliable signal for shock but conditioned poorly insofar as its proclivity to elicit overt conditioned defensive behavior. This state of affairs would seem to fall outside the dichotomy between the strength and the form of conditioning.

We are suggesting, on the basis of the present data, that, in addition to the possibility that the light is a poor CS, one can consider interesting accounts of the modality effect that are based on differences in behavior arising as phylogenetic adaptations to different selection pressures.

\section{REFERENCES}

Baker, A. G., Mercier, P., Gaber, J., \& Baker, P. A. Contextual conditioning and the US preexposure effect in conditioned fear. Journal of Experimental Psychology: Animal Behavior Processes, 1981, 7, 109-128.

Blanchard, R. J., \& Blanchand, D. C. Crouching as an index of fear. Journal of Comparative and Physiological Psychology, $1969,67,370-375$.

Bolles, R. C., \& Collien, A. C. The effect of predictive cues on freezing in rats. Animal Learning \& Behavior, 1976, 4, 6-8.

Bolles, R. C., \& Fangelow, M. S. Endorphins and behavior. Annual Review of Psychology, 1982, 33, 87-101.

Bouton, M. E., \& Bolle8, R. C. Conditioned fear assessed by freezing and by the suppression of three different baselines. Animal Learning \& Behavior, 1980, 8, 429-434.

EDWARDS, A. L. Experimental design in psychological research (4th ed.). New York: Holt, Rinehart \& Winston, 1972.

Fanselow, M. S. Naloxone and Pavlovian fear conditioning. Learning and Motivation, 1981, 12, 398-419.

Fanselow, M. S., \& BAackes, M. P. Conditioned fear-induced opiate analgesia on the Formalin test: Evidence for two aversive motivational systems. Learning and Motivation, 1982, 13, 200-221.

Fanselow, M. S., \& Sigmundi, R. A. The enhancement and reduction of defensive fighting by naloxone pretreatment. Physiological Psychology, 1982, 10, 313-316.

Fangelow, M. S., Sigmundi, R. A., \& Bolles, R. C. Naloxone pretreatment enhances shock-elicited aggression. Physiological Psychology, 1980, 8, 369-371.
Holland, P. C. Conditioned stimulus as a determinant of the form of the Pavlovian conditioned response. Journal of Experimental Psychology: Animal Behavior Processes, 1977, 3, 77-104.

Holland, P. C. The effects of qualitative and quantitative variation in the US on individual components of Pavlovian appetitive conditioned behavior in rats. Animal Learning \& Behavior, 1979, 7, 424-432.

Holl1s, K. L. Pavlovian conditioning of signal-centered action patterns and autonomic behavior: A biological analysis of function. In J. S. Rosenblatt, R. A. Hinde, C. Beer, \& M. Busnel (Eds.), Advances in the study of behavior (Vol. 12). New York: Academic Press, 1982.

JacoBs, W. J., \& LoLondo, V. M. Constraints on Pavlovian aversive conditioning: Implications for avoidance learning in the rat. Learning and Motivation, 1980, 11, 427-455.

Jenkins, H. M., Barnes, R. A., \& Barrera, F. J. Why autoshaping depends on trial spacing. In C. M. Locurto, H. S. Terrace, \& J. Gibbon (Eds.), Autoshaping and conditioning theory. New York: Academic Press, 1981.

Kamin, L. J. Predictability, surprise, attention, and conditioning. In B. A. Campbell \& R. M. Church (Eds.), Punishment and aversive behavior. New York: Appleton-Century-Crofts, 1969.

Karpicke, J., Cristoph, G., Peterson, G., \& Hearst, E. Signal location and positive versus negative conditioned suppression in the rat. Journal of Experimental Psychology: Animal Behavior Processes, 1977, 3, 105-118.

Linwick, D., Patterson, J., \& Overmier, J. B. On inferring selective association: Methodological considerations. Animal Learning \& Behavior, 1981, 9, 508-512.

Marlin, N. A. Contextual associations in trace conditioning. Animal Learning \& Behavior, 1981, 9, 519-523.

Oding-SMEE, F. J. The overshadowing of background stimuli by an informative $\mathrm{CS}$ in aversive Pavlovian conditioning with rats. Animal Learning \& Behavior, 1978, 6, 43-51. (a)

Oding-SmeE, F. J. The overshadowing of background stimuli: Some effects of varying amounts of training and UCS intensity. Quarterly Journal of Experimental Psychology, 1978, 30, 737-746. (b)

RATNER, S. C. Comparative aspects of hypnosis. In J. E. Gordon (Ed.), Handbook of experimental and clinical hypnosis. New York: Macmillan, 1967.

Rescorla, R. A. Informational variables in Pavlovian conditioning. In G. H. Bower (Ed.), The psychology of learning and motivation (Vol. 6). New York: Academic Press, 1972.

ShetTLE worth, S. J. Stimulus relevance in the control of drinking and conditioned fear responses in domestic chicks (Gallus gallus). Journal of Comparative and Physiological Psychology, 1972, 80, 175-198.

Sigmundi, R. A., Bouton, M. E., \& Bolues, R. C. Conditioned freezing in the rat as a function of shock intensity and CS modality. Bulletin of the Psychonomic Society, 1980, 15, 254-256.

VESTAL, B. M. Development of the immobility response (animal hypnosis) in two species of deermice (Peromyscus). Animal Learning \& Behavior, 1975, 3, 11-15.

Winer, B. J. Statistical principles in experimental design. New York: McGraw-Hill, 1962.

\section{NOTE}

1. The results in this report are presented in terms of percentage freezing scores. These were calculated for each animal on each trial by dividing the total number of behavior samples (10) during a CS or a pre-CS period into the number of freezing samples for the period; this proportion was then multiplied by 100 to obtain a percentage freezing score.

(Manuscript received October 2, 1981; revision accepted for publication February $8,1983$. 